www.jmscr.igmpublication.org

Index Copernicus Value: 79.54

ISSN (e)-2347-176x ISSN (p) 2455-0450

crossref DOI: https://dx.doi.org/10.18535/jmscr/v7i5.123

\title{
Consuming Tea: A Healthy Habit or a Health Hazard
}

\author{
Author \\ Dr (Colonel) Gurmeet Singh Sarla \\ Classified Specialist Surgery \\ Military Hospital Devlali, Nasik, Maharshtra, India Pin: 422401
}

\begin{abstract}
Consuming tea has been believed to be a health promoting habit since ages. Leaves of tea plant 'Camellia sinensis' has been found to have medicinal benefits. Types of tea based on processing or harvested leaf development are black tea, green tea, white tea and oolong tea. This review covers findings on the therapeutic properties and anticancer health benefits of green and black tea. Both green tea and black tea have a positive effect on human health.

Keywords: Tea, Camellia sinensis, health benefits.
\end{abstract}

\section{Introduction}

Tea is the cheapest beverage consumed by humans next to water and it began in China more than 3000 years ago. It became popular in Britain in the 17 th century and is consumed by two third of the world's population. Consuming tea has been believed to be a health promoting habit since ages. Leaves of tea plant 'Camellia sinensis' has been found to have medicinal benefits. Types of tea based on processing or harvested leaf development are black tea (fermented), green tea (non-fermented) and oolong tea (semi-fermented). Green tea is produced by immediately steaming the freshly harvested leaves to prevent fermentation, yielding a dry, stable product. This steaming process destroys the enzymes responsible for breaking down the colour pigments in the leaves and allows the tea to maintain its green colour during the subsequent rolling and drying processes. Tea leaves are allowed to ferment before being either smoke fired, flame fired or steamed to make black tea. Oolong tea is produced by a partial oxidation of the leaf, intermediate between the process for green and black tea. ${ }^{1}$ Studies have brought out that poly-phenolic compounds present in green and black tea prevents atherosclerosis and coronary artery disease. It also has anti-aging, antibacterial, anti-cancer, anti-obesity, antiinflammatory and anti-diabetic effects. ${ }^{2}$ This review covers findings on the therapeutic properties and anticancer health benefits of green and black tea.

\section{Materials}

This article describes the evidences from clinical and epidemiological studies in the prevention of chronic diseases like cancer and cardiovascular diseases and general health promotion associated with tea consumption. 


\section{Discussion}

The second emperor of China, Shen Nung, is believed to have discovered tea when the leaf of the plant Camellia sinensis blew into his cup of hot water $(2737 \mathrm{BCE})$. Tea is a popular drink around the world due to its pleasant taste and perceived health effects. The health benefits associated with consumption of tea may be related to the polyphenols present. Polyphenols have been found to have antioxidant, antiviral, and antiinflammatory activities; modulate detoxification enzymes; stimulate immune function and decrease platelet aggregation. ${ }^{3}$ Green tea has been extensively studied for its health benefits, including cancer chemopreventive and chemotherapeutic effects ${ }^{1}$ but emerging data shows that black tea (gun powder tea) may possess similar health promoting attributes. The total polyphenol content of green and black teas is similar, but with different types of flavonoids present due to the degree of oxidation during processing. 4

There is another type of tea, the white tea which has a different harvesting time,this is done when the buds are still covered by fine white hair and they are not fully open. Oolong tea is manufactured mainly in Taiwan and is produced with a shorter fermentation period and has taste and colour somewhere between green tea and black tea. ${ }^{5}$

Skin cancer: Tea has been shown to have a protective effect against squamous cell carcinoma. Concentration of tea, brewing time and beverage temperature influence the protective effects of hot black tea in relation to squamous cell carcinoma of the skin. ${ }^{6}$ Tea also has a protective effect against cutaneous malignant melanoma. ${ }^{7}$

Prostatic cancer: Green tea has been found to be protective against Prostatic cancer and the risk declined with increasing frequency, duration and quantity of green tea consumption. ${ }^{8}$ Green tea extracts are very rich in catechins and have been recently used as a chemo-preventive agent against Prostatic cancer. $^{9}$
Lung cancer: Tea drinking was associated with reduced risk of lung cancer in male cigarette smokers in a case control study in Uruguay. ${ }^{10}$ Consumption of green tea was associated with a reduced risk of lung cancer among non-smoking women and the risk decreased with increasing consumption. $^{11}$

Breast cancer: In a meta-analysis published by Sun et al., ${ }^{13}$ studies were examined and data on consumption of either green tea or black tea, or both in relation to breast cancer risk was provided. $^{12}$ Consumption of green tea was associated with a reduced risk of developing breast cancer in a case-control study with breast cancer confirmed patients. ${ }^{13}$ Tea has been shown to have anticarcinogenic effects against breast cancer in experimental studies. ${ }^{14}$

Esophageal cancer: Consumption of green tea was associated with a lower risk of esophageal cancer in a case-control study of esophageal cancer patients in Shanghai. ${ }^{15}$ A most recent metaanalysis shows that the consumption of green tea and coffee appears to reduce esophageal cancer but black tea does not. ${ }^{16}$

Colonic cancer: It has been reported in a study that consumption of black tea reduces colon cancer risk in both men and women. ${ }^{17}$ Inverse relationship of tea consumption with cancer of the colon has been widely reported. ${ }^{18}$

Liver cancer: Green tea consumption has been associated with a moderate reduction in risk for primary liver cancer. ${ }^{19}$ The proliferation of hepatic stellate cells is closely related to the progression of liver fibrosis in chronic liver diseases, and EGCG (epigallocatechin gallate) the most potent catechin present in green tea, has a potential inhibitory effect on the proliferation of these cells. $^{20}$

Cardiovascular system: Green tea consumption prevents appearance of atherosclerotic plaque in blood vessels. Its causes decreased absorption of triglycerides and cholesterol and these findings are in accordance with the fact that it increases excretion of fat. ${ }^{21} \mathrm{~A}$ randomized control study in obese hypertensive patients showed that green tea 
extract may significantly reduce hypertension, insulin resistance, total and LDL cholesterol, inflammation, and levels of markers of oxidative stress. ${ }^{22}$ Green tea may have some antithrombotic effects. $^{23}$

Diabetes: A lowered diabetes risk has been observed in women consuming green tea. ${ }^{24}$ Green tea may result in lower fasting glucose levels but no significant $\mathrm{HbA} 1 \mathrm{c}$ changes. ${ }^{25}$ Insulin resistance may be improved by the antioxidant protective function of the polyphenols. ${ }^{26}$

Arthritis: In a study in Britain, it was found that those who drank tea had greater bone mineral density compared to those who did not drink tea. ${ }^{27}$ Parkinson's disease: A case control study was conducted in China to examine the relationship between coffee and tea drinking and risk of Parkinson's disease. It was found that one unit of coffee and tea (3 cups/day for 10 years) would lead to $22 \%$ and $28 \%$ risk reduction, respectively, of Parkinson's disease demonstrating a dosedependent protective effect of coffee and tea in an ethnic Chinese population. ${ }^{28}$ In a Finnish study It was noted that subjects who habitually drank $\geq 3$ cups of tea/day had a reduced risk of incident Parkinson's disease. ${ }^{29}$ In the Singapore Chinese Health Study, an inverse relationship of black tea with Parkinson's disease risk that was found while green tea was unrelated to Parkinson's disease risk. $^{30}$

Anti-infective properties: Green tea extract potentially could be used in a mouth wash as a preventative for tooth decay and periodontal disease because of its strong antibacterial properties. $^{31}$ Epigallocatechin gallate, the most active component of green tea, has antiviral, antibacterial, and antifungal properties. ${ }^{32}$

Depression: The consumption of greater quantities of tea, 4 or more cups compared to 1 or less, may provide some protection from depression. ${ }^{33}$

Adverse effects: EGCG (Epigallocatechin gallate) of green tea extract is cytotoxic, and higher consumption of green tea can have cytotoxic effects on liver cells. ${ }^{34}$ Traces of heavy metals contaminate tea samples not only because of the tendency of these elements to bioaccumulate, ${ }^{35}$ but also the due to the processing methods used before tea is made commercially available. ${ }^{36}$ Certain tea samples contain quantities of iron sufficient to cause deleterious effects in human beings. ${ }^{37}$ Excessive amounts of GTC (green tea catechins) used for weight reduction may cause hepatic toxicity. ${ }^{38}$

\section{Conclusion}

Tea contains polyphenols and other components that may reduce the risk of developing chronic diseases such as cancer, cardiovascular diseases, arthritis and diabetes. Tea acts as a chemopreventive agent against Prostatic cancer. Definitive conclusions regarding the protective effects of green tea have been seen from well-designed epidemiological studies. Both green tea and black tea have a positive effect on health but effects of green tea have been extensively studied.1-6 cups/ day of tea have beneficial effects on health. More than 8 cups of tea per day may have toxic effects on human health.

\section{References}

1. Mukhtar H, Ahmad N. Tea polyphenols: prevention of cancer and optimizing health. Am J ClinNutr. 2000;71:1698S702S. discussion 1703S-4S.

2. Zaveri N.T. Green tea and its polyphenoliccatechins: Medicinal uses in cancer and non cancer applications. Life Sci. 2006;78(18):2073-80.

3. Frankel E.N, Finley J.W. How to standardize the multiplicity of methods to evaluate natural anti- oxidants. J Agric Food Chem. 2008;56(13):4901-8.

4. Stangl V, Lorenz M, Stangl K. The role of tea and tea flavonoids in cardiovascular health. MolNutr Food Res. 2006;50:21828.

5. Duthie G.G, Crozier A. Beverages. In: Goldberg G, editor. In Plants: Diet and Health. London: British Nutrition 
Foundation, Chapman Hall; 2003. pp. 147-182.

6. Hakim IA, Harris RB, Weisgerber UM. Tea intake and squamous cell carcinoma of the skin: influence of type of tea beverages. Cancer Epidemiol Biomarkers Prev. 2000;9:727-31.

7. Naldi L, Gallus S, Tavani A, Imberti GL, La Vecchia C. Risk of melanoma and vitamin A, coffee and alcohol: a casecontrol study from Italy. Eur J Cancer Prev. 2004;13:503-8.

8. Jian L, Xie LP, Lee AH, Binns CW. Protective effect of green tea against prostate cancer: a case-control study in southeast China. Int J Cancer. 2004; 108:130-5.

9. Jian L, Xie L.P, Lee A.H, editors. et al. Protective effect of green tea against prostate cancer: A case-control study in southeast China. Int J Cancer. 2004;108: 130-5.

10. Mendilaharsu M, De Stefani E, DeneoPellegrini H, Carzoglio JC, Ronco A. Consumption of tea and coffee and the risk of lung cancer in cigarette-smoking men: a case-control study in Uruguay. Lung Cancer. 1998;19:101-7.

11. Zhong L, Goldberg MS, Gao YT, Hanley JA, Parent ME, Jin F. A population-based case-control study of lung cancer and green tea consumption among women living in Shanghai, China. Epidemiology. 2001;12:695-700.

12. Sun CL, Yuan JM, Koh WP, Yu MC. Green tea, black tea and breast cancer risk: a meta-analysis of epidemiological studies. Carcinogenesis. 2006;27:1310-5.

13. Zhang M, Holman CD, Huang JP, Xie X. Green tea and the prevention of breast cancer: a case-control study in Southeast China. Carcinogenesis. 2007;28:1074-8.

14. Min Zhang C, D'Arcy JH, Jiang-ping H, Xing $\mathrm{X}$. Green tea and the prevention of breast cancer: a case-control study in
Southeast China. Carcinogenesis. 2005;28 (5):1074-1078.

15. Gao YT, McLaughlin JK, Blot WJ, Ji BT, Dai Q, Fraumeni JF., Jr Reduced risk of esophageal cancer associated with green tea consumption. J Natl Cancer Inst. 1994;86:855-8.

16. Zheng JS, Yang J, Fu YQ, Huang T, Huang YJ, Li D. Effects of green tea, black tea, and coffee consumption on the risk of esophageal cancer: a systematic review and meta-analysis of observational studies. Nutrition and Cancer. 2013;65 (1):1-16.

17. Su LJ, Arab L. Tea consumption and the reduced risk of colon cancer -- results from a national prospective cohort study. Public Health Nutr. 2002;5:419-25.

18. Koo MW, Cho CH. Pharmacological effects of green tea on the gastrointestinal system. Eur J Pharmacol. 2004;500:17785.

19. Sing MF, Yang WS, Gao S, Gao J, Xiang YB. Epidemiological studies of the association between tea drinking and primary liver cancer: a meta-analysis. Eur J Cancer Prev. 2011;20:157-65.

20. Sakata R, Ueno T, Nakamura T, Sakamoto M, Torimura T, Sata M. Green tea polyphenols epigallocatechin-3-gallate inhibits platelet-derived growth factorinduced proliferation of human hepatic stellate cell line LI90. J Hepatol. 2004; 40:52-59.

21. Raederstorff DG, Schlachter MF, Elste V, Weber P. Effect of EGCG on lipid absorption and plasma lipid levels in rats. $\mathrm{J}$ NutrBiochem. 2003;14:326-32.

22. Bogdanski P, Suliburska J, Szulinska M, Stepien M, Pupek-Musialik D, Jablecka A. Green tea extract reduces blood pressure, inflammatory biomarkers, and oxidative stress and improves parameters associated with insulin resistance in obese, 
hypertensive patients. Nutrition Research. 2012;32:421-427.

23. Kang W-S, Lim I-H, Yuk D-Y, et al. Antithrombotic activities of green tea catechins and (-)-epigallocatechin gallate. Thrombosis Research. 1999;96 (3):229237.

24. Iso $H$, Date $C$, Wakai $K$, Fukui $M$, Tamakoshi A. The relationship between green tea and total caffeine intake and risk for self-reported type 2 diabetes among Japanese adults. Ann Intern Med. 2006; 144:554-62.

25. Maeda-Yamamoto M. Human clinical studies of tea polyphenols in allergy or life style-related diseases. Current Pharmaceutical Design. 2013;19(34): 6148-6155.

26. Yan J, Zhao Y, Suo S, Liu Y, Zhao B. Green tea catechins ameliorate adipose insulin resistance by improving oxidative stress. Free Radical Biology and Medicine. 2012;52(9):1648-1657.

27. Hegarty VM, May HM, Khaw KT. Tea drinking and bone mineral density in older women. Am J ClinNutr. 2000;71:1003-7.

28. Tan EK, Tan C, Fook-Chong SM, et al. Dose-dependent protective effect of coffee, tea, and smoking in Parkinson's disease: a study in ethnic Chinese. J Neurol Sci. 2003;216:163-7.

29. Hu G, Bidel S, Jousilahti P, Antikainen R, Tuomilehto J. Coffee and tea consumption and the risk of Parkinson's disease. Movement Disorders. 2007;22:2242-8.

30. Tan LC, Koh WP, Yuan JM, et al. Differential effects of black versus green tea on risk of Parkinson's disease in the Singapore Chinese Health Study. Am J Epidemiol. 2008;167:553-60.

31. Araghizadeh A, Kohanteb J, Fani MM. Inhibitory activity of green tea (Camellia sinensis) extract on some clinically isolated cariogenic and periodontopathic bacteria. Medical Principles and Practice. 2013;22(4):368-372.
32. Steinmann J, Buer J, Pietschmann T, Steinmann E. Anti-infective properties of epigallocatechin-3-gallate (EGCG), a component of green tea. British Journal of Pharmacology. 2013;168:1059-1073.

33. Pham NM, Nanri A, Kurotani K, et al. Green tea and coffee consumption is inversely associated with depressive symptoms in a Japanese working population. Public Health Nutrition. 2013

34. Schmidt M, Schmitz HJ, Baumgart A, Guedon D, Netsch MI, Kreuter MH, Schmidlin CB, Schrenk D. Toxicity of green tea extracts and their constituents in rat hepatocytes in primary culture. Food Chem Toxicol. 2005;43:307-314.

35. Achudume AC, Owoeye D. Quantitative assessment of heavy metals in some tea marketed in Nigeria - Bioaccumulation of heavy metals in tea. Health. 2010;2:1097100.

36. Marcos A, Fisher A, Ree G, Hill SJ. Preliminary study using trace element concentration and a chemometrics approach to determine the geological origin of tea. J Agric At Spectrom.

37. Salahinejad M, Aflaki F. Toxic and essential mineral elements content of black tea leaves and their tea infusions consumed in Iran. Biol Trace Elem Res. 2010; 134:109-17.

38. Yang C.S, Wang H, Li G.X, Yang Z, Guan $\mathrm{F}$, Jin $\mathrm{H}$. Cancer prevention by tea: Evidence from laboratory studies. Pharmacol Res. 2011;64(2):113-22. 